ISSN 0103-8478

\title{
Bebidas lácteas com soro de queijo e frutas
}

\author{
Dairy beverage containing cheese whey and fruit
}

\author{
Amanda de Morais Oliveira Siqueira ${ }^{I}$ Erilane de Castro Lima MachadoII \\ Tânia Lúcia Montenegro Stamford ${ }^{\text {III }}$
}

\section{- REVISÃo BIBLIOGRÁFICA -}

\section{RESUMO}

O soro do leite é um subproduto de relevância da indústria de queijos por ser produzido em grande volume e conter aproximadamente 55\% dos nutrientes do leite. O seu aproveitamento industrial em produtos da alimentação humana ainda é considerado baixo, visto que a alta concentração de minerais proporciona uma baixa aceitação sensorial dos alimentos que o contém. Dessa forma, têm-se desenvolvido bebidas, principalmente as fermentadas, que apresentam novos sabores e aromas, com o objetivo de recuperar essa importante fonte de nutrientes para a cadeia alimentar humana. Observa-se, portanto, que a utilização do soro de queijo enriquece os produtos que os contém e evita o descarte diretamente no solo, na rede pública de esgoto, rios e lagos, minimizando o impacto negativo, conforme abordado nesta revisão.

Palavras-chave: aproveitamento de resíduos, bebidas, impacto ambiental, soro de queijo.

\section{ABSTRACT}

The whey is a relevant by-product in the cheese industry for being produced in large volume and for containing approximately $55 \%$ of its nutrients from milk. Its industry performance upon human nutrition products is still considered low, because the high concentration of minerals provides a low sensorial acceptation of food. Thus, beverages have been developed, mainly the fermented ones that display new flavors and aromas, aiming at recovering such important source of nutrients for the human food chain. It is observed, therefore, that the use of cheese whey enriches the products that contain them and avoid the culling directly in the soil, in the sewage system, rivers, and lakes, minimizing the negative impact, as discussed in this review.

Key words: sustainable use of residues, beverages, environmental damage, cheese whey.

\section{INTRODUÇÃO}

Soro é o líquido residual obtido a partir da coagulação do leite destinado à fabricação de queijos ou de caseína (BRASIL, 2005). Esse subproduto retém cerca de $55 \%$ dos nutrientes do leite, sendo considerado relevante, tendo em vista o volume produzido e sua composição nutricional (LEITE et al., 2012).

Dados do United States Department of Agriculture (USDA, 2012) reportam a produção de 670.000 toneladas de queijos no Brasil em 2011, com estimativas do país produzir 700.000 toneladas de queijos em 2012. Em média, para fabricação de um quilo de queijo são necessários dez litros de leite, com recuperação de nove litros de soro (BARBOSA et al., 2010). Assim, calcula-se que a geração de soro decorrente dos queijos produzidos no Brasil é relevante, com estimativas de um valor próximo a 6,03 milhões de toneladas.

Por esse motivo, há uma preocupação recorrente em gerar aplicabilidade ao soro de queijo em novos alimentos, visto que, no território brasileiro, cerca de $50 \%$ do soro não é aproveitado, gerando desperdícios nutricional, financeiro e impactos ambientais relevantes, já que é um resíduo com alto teor orgânico (MAGALHÃES et al., 2011).

$\mathrm{O}$ teor de lactose e outros nutrientes faz do soro uma matéria-prima potencial ao desenvolvimento de micro-organismos probióticos, viabilizando

\footnotetext{
'Departamento de Tecnologia Rural, Universidade Federal Rural de Pernambuco (UFRPE), Rua Dom Manoel de Medeiros, s/n, Dois Irmãos, 52171-900, Recife, PE, Brasil. E-mail: amanda.morais@gmail.com. Autor para correspondência.

${ }^{\text {II } C e n t r o ~ A c a d e ̂ m i c o ~ d e ~ V i t o ́ r i a, ~ U n i v e r s i d a d e ~ F e d e r a l ~ d e ~ P e r n a m b u c o ~(U F P E), ~ V i t o r i a ~ d e ~ S a n t o ~ A n t a ̃ o, ~ P E, ~ B r a s i l . ~}$

${ }^{I I I}$ Departamento de Nutrição, Centro de Ciências da Saúde (CCS), UFPE, Recife, PE, Brasil.
} 
a produção de bebidas lácteas fermentadas (MAGALHÃES et al., 2011), já que o soro in natura apresenta baixa aceitação sensorial pelo alto teor de sais minerais (SOARES et al., 2011).

Associado ao processo de fermentação, a adição de frutas tem melhorado as características de aromas e sabor das bebidas lácteas, visto que a incorporação de diferentes proporções de suas polpas resulta no aumento da aceitabilidade (OLIVEIRA, 2006; CALDEIRA et al., 2010; MOREIRA et al., 2010; SILVA et al., 2010). Entre os principais interesses no uso de frutas para melhorar a aceitação das bebidas lácteas, estão os relacionados com as estratégias de marketing voltadas a esses produtos, cujo objetivo é o oferecimento de novas opções de alimentos saudáveis aos consumidores (ROUTRAY \& MISHRA, 2011).

É importante ressaltar que o hábito no consumo de frutas do brasileiro vem aumentando. FACHINELLO et al. (2011) afirmam que este fato é influenciado por fatores econômicos e de produção, já que o Brasil é o terceiro maior produtor mundial de frutas, com uma produção de 40 milhões de toneladas ao ano.

MURPHY et al. (2012) afirmam que, independente da espécie, o consumo de frutas está frequentemente associado aos efeitos de seus fitonutrientes à saúde humana. Dentre os nutrientes, as fibras alimentares são importantes nas formulações das bebidas lácteas fermentadas, visto que são completa ou parcialmente fermentados no intestino grosso, fornecendo energia para o desenvolvimento de bifidobactérias e lactobacilos, ressaltando que as oligofrutoses merecem ênfase nesse grupo (CICHOSKI et al., 2008).

Assim, observa-se que o interesse mercadológico em alcançar o consumidor através da associação do soro de queijo às frutas está embasado nas recomendações nutricionais quanto ao aumento no consumo de frutas e hortaliças. Diante do exposto, esta revisão objetiva sumarizar o contexto atual e perspectivas para aplicabilidade do excedente de soro de queijo e de frutas pela indústria, contextualizando a aplicação desses alimentos na produção de bebidas lácteas com potencialidades funcionais.

Para a pesquisa, foram consultados 147 artigos nacionais e internacionais disponíveis nas bases de dados SciELO, ScienceDirect (Elsevier), SpringerLink, Web of Science e demais publicações de periódicos em várias bases de dados nas diversas áreas das Ciências e Tecnologia de Alimentos, além de legislações e outros documentos pertinentes. Restringiu-se às publicações em língua inglesa e portuguesa, entre os anos de 2002 a 2012. Foram utilizadas as palavras chave em português e seus correspondentes em inglês: soro de queijo, fruta, bebida láctea, bebida láctea fermentada, probiótico. Dentre os artigos consultados, foi dada prioridade aos artigos originais, com o objetivo de desenvolvimento de novas formulações de bebidas lácteas a base de soro e polpas de fruta no Brasil, mas não deixando de serem consultados artigos originais e revisões de literatura internacionais sobre o tema.

Valor nutricional e impacto ambiental do soro de queijo

A expressiva produção de leite, e a aceitação do consumidor por grande número de produtos lácteos, possibilitam o desenvolvimento de diversos tipos de queijo, os quais geram um importante montante de resíduo líquido $(85 \%$ a $95 \%$ do volume total de leite), denominado de soro. Esse soro também é obtido a partir da fabricação de caseína ou produtos lácteos similares (DRAGONE et al., 2009; BARBOSA et al., 2010).

De acordo com PESCUMA et al. (2010), o soro é composto de água (93\%), lactose (5\%), proteínas $(0,85 \%)$, uma quantidade mínima de gordura $(0,36 \%)$ e minerais $(0,53 \%)$ incluindo $\mathrm{NaCl}$ e $\mathrm{KCl}$, sais de cálcio (principalmente fosfato) e outros. $\mathrm{O}$ soro também contém ácido lático $\left(0,5 \mathrm{~g} \mathrm{~L}^{-1}\right) \mathrm{e}$ ácido cítrico, compostos nitrogenados não-proteicos (ureia e ácido úrico) e vitaminas do complexo B (DRAGONE et al., 2009).

HARAGUCHI et al. (2006) afirmam que as proteínas do soro do leite (alfa e beta-lactoglobulina, albumina de soro bovino, imunoglobulinas) apresentam um excelente perfil de aminoácidos essenciais, caracterizando-as como proteínas de alto valor biológico. Além disso, possuem peptídeos bioativos (exorfinas, imunopeptídeos e fosfopeptídeos), que conferem a essas proteínas diferentes propriedades funcionais.

Evidências apontam também que, quando manejado de forma inadequada, o soro pode atuar como agente de poluição ambiental (MAGALHÃES et al., 2011). O excedente desse subproduto é um dos maiores problemas enfrentados pelas indústrias de laticínios, principalmente as de pequeno e médio porte, frente ao custo elevado do tratamento. Por isso, algumas indústrias optam pelo seu descarte diretamente na rede pública, rios e lagos (FLORENTINO et al., 2005).

O poder poluente do soro é aproximadamente 100 vezes maior que o esgoto doméstico. Assim, se lançado em cursos d'água 
reduz a vida aquática, devido à demanda bioquímica de oxigênio (30.000mg a 50.000mg de oxigênio/ litro de soro) e, se descartado no solo, compromete a estrutura físico-química, diminuindo o rendimento da colheita (BARBOSA \& ARAÚJO, 2007; MOREIRA et al., 2010; LEITE et al., 2012).

O alto percentual de água presente no soro de queijo in natura torna dispendiosa sua desidratação e, por ser perecível, agrava o problema, impossibilitando o armazenamento prolongado. Assim, pesquisas direcionam seu aproveitamento aos produtos em que se possa utilizá-lo na forma líquida (SERPA et al., 2009), onde o soro recebe aplicações representativas nas formulações de bebidas lácteas fermentadas.

PEREIRA et al. (2009) investigaram as preocupações ambientais de seis agroindústrias exportadoras de laticínios em Minas Gerais. Quanto ao destino do soro, quatro das seis empresas vendiam esse resíduo para fabricantes de bebidas lácteas. Uma das empresas gerava soro de queijo, mas o enviava à estação de tratamento de efluentes e a outra utilizava todo o leite para obtenção de seu produto e, portanto, não gerava esse resíduo. Vale salientar que as preocupações ambientais das agroindústrias estudadas relacionavam-se essencialmente aos aspectos legais e econômicos, sendo a variável ambiental apenas o meio para atingir os objetivos empresariais. Essas observações confirmam as considerações de SERPA et al. (2009), de que poucas empresas apresentam efetiva preocupação ambiental quanto ao destino correto do soro de queijo.

Em Mossoró-RN, JERÔNIMO et al. (2012) avaliaram a qualidade ambiental e sanitária de 12 laticínios. Os autores observaram que na maioria das indústrias os efluentes gerados no processamento dos produtos lácteos eram dispostos na rede de esgoto sem tratamento, eram destinados aos produtores de suínos da região, ou ainda, depositados em lagoas de captação particular, sem assegurar as normas técnicas de construção, com possibilidade de poluir o solo e o subsolo da área de descarte.

\section{Bebidas lácteas a base de soro e frutas}

A busca incessante por novos produtos fez a indústria de alimentos perceber que os consumidores estão cada vez mais preocupados com sua saúde, e que desejam ingerir alimentos saudáveis e, de preferência, capazes de prevenir doenças. Ao longo dos anos, a indústria reconheceu também que o soro de queijo é bastante versátil e contribui na produção de alimentos lácteos fermentados por microorganismos probióticos e, por isso, esses produtos estão assumindo grande popularidade frente aos que procuram por alimentos funcionais (BALDISSERA et al., 2011).

Alimentos funcionais são aqueles que garantem efeito nutricional adequado e podem demonstrar benefícios adicionais em uma ou mais funções do organismo, proporcionado melhorias do estado de saúde e bem estar ou redução do risco de doenças. Os probióticos representam o alimento funcional típico, e são definidos como suplemento microbiano vivo que afetam beneficamente o hospedeiro, melhorando o equilíbrio microbiano intestinal (FAO/WHO, 2002; SOARES et al., 2011).

PESCUMA et al. (2010) esclarecem que os benefícios do uso de bactérias láticas na fermentação do soro estão associados à intensa atividade metabólica sobre carboidratos, lipídeos, proteínas e peptídeos alergênicos que nele estão presentes. Assim, as bactérias promovem contribuição na digestibilidade, preservação, melhoria da textura e perfil sensorial do alimento, visto que há redução do teor de lactose, produção de ácido lático que contribui para o flavor e textura do produto final.

Desse modo, uma das principais alternativas de utilização do soro compreende a formulação de bebidas lácteas, que, de acordo com a legislação brasileira (BRASIL, 2005), é o produto resultante da mistura do leite e soro de queijo ou substância alimentícia, cuja base láctea represente no mínimo 51\% dos ingredientes. A aromatização dessas bebidas é normalmente melhorada com o acréscimo de polpas de frutas, tornando a aceitação sensorial do produto mais representativa. Além disso, o uso de polpa de fruta em bebidas lácteas fermentadas é uma opção interessante para solucionar o problema do excedente de produção e/ou pouco aproveitamento de frutos que não estão aptos ao consumo "de mesa" ou para exportação (SANTOS et al., 2008).

Visando a melhorar a aplicabilidade de frutas que apresentam alta perecibilidade e deficiente conservação pós-colheita, diversos estudos têm promovido a inserção desses alimentos na cadeia produtiva de bebidas lácteas fermentadas e não fermentadas. Assim, MATOS (2009) elaborou seis formulações de bebida láctea com $25 \%$ de polpa de graviola, variando a proporção de açúcar $(12 \% ; 14 \%$ e $16 \%)$ e espessante $(0,4 \%, 0,8 \%$ e $1,2 \%)$. O soro foi utilizado em proporções suficientes para totalizar $100 \%$ em cada formulação. Os resultados mostraram que mais de $12 \%$ de açúcar nas bebidas diminuiu a preferência pelos consumidores, pois a doçura sobressai ao sabor e aroma da graviola, mas o uso de espessante aumenta a sua preferência. $\mathrm{O}$ estudo mostrou que a bebida láctea de graviola é considerada mais nutritiva que a bebida 
láctea fermentada e o leite fermentado sem adição de frutas, pois apresentou maior fonte de proteínas, carboidratos e minerais, além de mais saudável, em função do menor teor de gordura.

A importância da adição da polpa de graviola a uma bebida láctea é promover a inclusão dessa fruta em mais uma classe de alimentos com potencial mercadológico, visto que a graviola é considerada uma boa fonte natural de antioxidantes (BASKAR et al., 2007), além de conter carboidratos, proteínas, ácido fólico, cálcio, fósforo, ferro, vitamina C, B1 e B2 e fibras (DEMBITSKY et al., 2011).

Alguns alimentos exercem efeito protetor promovido por substâncias antioxidantes, como vitamina $\mathrm{C}$, vitamina $\mathrm{E}$, carotenoides e os compostos fenólicos. Os antioxidantes são capazes de modular mecanismos envolvidos na manutenção de uma fisiologia saudável, com redução do início precoce de doenças relacionadas ao estresse oxidativo (ARUOMA et al., 2012).

Considerando essas características, SANTOS et al. (2006) desenvolveram uma bebida láctea fermentada com soro do queijo tipo mussarela $(20 \%, 40 \%, 60 \%$ e $80 \%)$, acrescida de polpa de umbu (Spondias tuberosa sp.). As características físicoquímicas e aceitação sensorial não apresentaram diferença significativa $(\mathrm{P}>0,05)$ para as formulações com $20 \%, 40 \%$ e $60 \%$ de soro, caracterizando a bebida com $60 \%$ de soro como a mais viável em termos de utilização do maior volume desse subproduto. Baseado no conceito de alimento probiótico, SILVA et al. (2010) elaboraram e avaliaram as características sensoriais de bebidas lácteas fermentadas sabor umbu-cajá (Spondias tuberosa x S. mombin), com diferentes proporções de soro de queijo $(0 \% ; 15 \%$; $30 \% ; 45 \% ; 60 \%)$. O estudo da preferência entre as bebidas não apresentou diferença significativa $(\mathrm{P}<0,05)$ entre as amostras com $0 \%, 15 \%, 30 \%$ e $45 \%$ de soro, permitindo a aplicabilidade da maior concentração possível de soro à fórmula da bebida proposta. Vale ressaltar que produtos a base de frutas do gênero Spondias destacam-se pelo sabor e aroma exótico, características que repercutem positivamente sobre o valor comercial. Além dos atributos sensoriais, frutas desse gênero apresentam importante composição em compostos bioativos com capacidade antioxidante (SILVA et al., 2012).

SANTOS et al. (2008) observaram que, das bebidas lácteas fermentadas com polpa de manga e diferentes concentrações de soro de queijo mussarela $(20 \%, 40 \%, 60 \%$ e $80 \%)$, a formulação com substituição de $40 \%$ de soro foi a mais aceita (termo hedônico "gostei muito"), com indicação de melhor textura e consistência, homogeneidade e sabor agradável. Adicionalmente, pode-se inferir que a aplicabilidade da manga é nutricionalmente recomendada, pois, além da composição em fibras, contém vários nutrientes bioativos como $\beta$-caroteno, ácido ascórbico, sais minerais e teor considerável de compostos fenólicos (FARAONI et al., 2012).

BRANDÃO et al. (2006) utilizaram soro de queijo para obtenção de uma bebida fermentada adicionada de polpa de abacaxi e observaram que, do ponto de vista sensorial, a bebida apresentou ótima aceitação, pois foi enquadrada no termo hedônico "gosto muito", além de oferecer os benefícios relacionados aos alimentos fermentados adicionados de extratos de frutas. De acordo com HOSSAIN \& RAHMAN (2011), o abacaxi possui alto valor nutritivo e é fonte de vitaminas A, C e do complexo B, cálcio, fósforo e ferro. Além disso, pode-se explicar a bioatividade funcional dessa fruta pela presença de compostos fenólicos que proporcionam uma boa ação antioxidante.

Em pesquisa com o objetivo avaliar o potencial comercial de uma bebida láctea probiótica de soro de queijo e polpa de açaí, ZOELLNER et al. (2009) verificaram que a bebida láctea controle (sem polpa de açaí) mostrou redução de um ciclo de log $\left(10^{6}-10^{5} \mathrm{UFC}_{\mathrm{mL}^{-1}}\right)$ na contagem de Bifidobacterium longum B1-05 e Lactobacillus acidophilus La14, após 21 dias de armazenamento, enquanto que a bebida com polpa de açaí apresentou contagens significativamente mais elevadas $\left(10^{7}-10^{8} \mathrm{UFC} \mathrm{mL}^{-1}\right)$ para ambos os micro-organismos estudados $(\mathrm{P}<0,05)$. A análise sensorial também demonstrou a existência de potencial comercial da bebida probiótica proposta. Além disso, deve-se considerar que a polpa de açaí exerce efeito prebiótico devido ao teor de fibras e que a produção de componentes lipídicos bioativos ( $\alpha$-linolênico e linoleico conjugado) é melhorada pela sua adição durante a fermentação da base láctea, oferecendo benefícios potenciais à saúde (ESPÍRITO SANTO et al., 2010).

Com o soro de queijo de manteiga e suco de acerola, CRUZ et al. (2009) produziram três formulações de bebida: B1 (50\% soro $+50 \%$ suco), B2 $(70 \%$ soro $+30 \%$ suco $)$, e B3 $(30 \%$ soro $+70 \%$ suco). Os resultados indicaram que B2 apresentou índices mais significativos em todos os atributos sensoriais, o que sugere a possibilidade de produção e comercialização da bebida. Do ponto de vista nutricional, todas as bebidas apresentaram-se como de baixo valor calórico e fonte de aminoácidos essenciais, e vitamina C (B1 e B2). FARAONI et al. (2012) destacam ainda que a acerola é um fruto 
com importante composição em antocianinas e carotenoides.

Bebidas lácteas com leite de búfala, diferentes níveis de iogurte e soro do queijo Tipo Frescal, e 5\% de polpa de morango foram desenvolvidas por CALDEIRA et al. (2010). Os testes de aceitação e preferência sensorial mostraram que as bebidas T1 (10\% leite, $10 \%$ soro e $80 \%$ iogurte) e T2 (10\% leite, $20 \%$ soro e $70 \%$ iogurte) apresentaram as maiores médias para os atributos sensoriais estudados (impressão global, aparência, consistência, sabor), não diferindo entre si $(\mathrm{P}>0,05)$, além das melhores condições quanto ao $\mathrm{pH}$, acidez titulável, gordura, proteína, viscosidade e cor. Destaca-se que as formulações com 30\% (T3), 40\% (T4) e 50\% (T5) de soro sofreram alterações de $\mathrm{pH}$, acidez, viscosidade e luminosidade $\left(\mathrm{L}^{*}\right)$, condições que podem ter influenciado negativamente no estudo de aceitabilidade e preferência das bebidas.

OLIVEIRA et al. (2006) também utilizaram polpa de morango para desenvolvimento de três formulações de bebida láctea fermentada com soro de queijo (10\%, 30\% e 50\%) e ferro quelado. Os resultados mostraram que a bebida láctea fermentada com $30 \%$ de soro foi considerada ideal para a produção por se enquadrar nas determinações legais de composição e por ter sido sensorialmente aceita.

Devido ao fato do morango ser um fruto bastante aceito pela população consumidora em geral, sua utilização como saborizante e aromatizante em bebidas lácteas é bastante significativa. Esse fato favorece a aceitação mercadológica e também o aporte de nutrientes especiais as bases lácteas tradicionais. As antocianinas presentes no morango proporcionam a cor vermelha, que é um importante e atrativo componente na aparência dos produtos, além de apresentarem considerável atividade anticarcinogênica e antiangiogênica (BORDIGNON JR et al., 2009).

Associado aos efeitos benéficos das frutas e da ação dos micro-organismos probióticos, o desenvolvimento de bebidas lácteas com soja é baseada na possibilidade de oferecer vantagens nutricionais adicionais ao consumidor. Assim, KRUGER et al. (2008) observaram que a formulação de uma bebida láctea probiótica com cultura mista de Streptococcus thermophilus, Lactobacillus bulgaricus, Lactobacillus acidophilus e Bifidobacterium, contendo $30 \%$ de extrato hidrossolúvel de soja; $36,6 \%$ de leite de vaca; $33,3 \%$ de soro e polpa de morango, foi considerada ideal sob o ponto de vista sensorial. Além disso, a bebida láctea apresentou células viáveis da cultura mista dentro dos padrões estabelecidos $\left(10^{6} \mathrm{UFC}^{-1}\right)$ até o $22^{\circ}$ dia, mas a qualidade sensorial (acidez bastante elevada) definiu o término do armazenamento no $25^{\circ}$ dia.

Outra bebida láctea fermentada probiótica sabor pêssego foi formulada com igual composição (30\% de extrato hidrossolúvel de soja; $36,6 \%$ de leite de vaca; $33,3 \%$ de soro de queijo) por KEMPKA et al. (2008). A aceitação sensorial foi semelhante, contudo observou-se que o uso da polpa de pêssego promoveu uma diferenciação na qualidade físico-química, visto que a acidez ficou bastante evidenciada a partir do 14을 dia de armazenamento, o que definiu o término da vida de prateleira da bebida.

Vale destacar que, embora a maioria das bebidas vegetais do mercado não sejam fermentadas, atualmente os produtos a base de soja e/ou cereais (arroz, cevada, trigo) têm apontado uma nova tendência com conquista de público. Misturas de base láctea, frutas, cereais ou leguminosas, quando submetidas à fermentação, apresentam melhores combinações para propriedades texturais, sensoriais e nutricionais. Ressalta-se ainda que além dos nutrientes básicos, quando submetida à fermentação, há redução de fatores antinutricionais pela hidrólise de proteínas e formação de peptídeos.

Diante dos diferentes estudos apresentados, observa-se que o desenvolvimento de produtos utilizando o soro de queijo é bastante promissor, pois as bebidas contendo esse tipo de soro, em destaque as bebidas lácteas fermentadas, são uma realidade no mercado brasileiro, porque já representam 25\% do mercado total de iogurtes no país (PFLANZER et al., 2010). Vale destacar ainda que a produção de derivados do leite é uma tendência, e a indústria deve se adequar à realidade de que a população consumidora detém conhecimentos e identificam o importante valor nutricional desses alimentos (OLIVEIRA et al., 2010). Por isso, a indústria deve buscar uma diferenciação de mercado, incluindo o aumento no uso de ingredientes exóticos e inovadores.

\section{CONSIDERAÇÕES FINAIS}

O crescimento das empresas de laticínios e o apelo da população consumidora por produtos que ofereçam sabor, saúde e conveniência tem impulsionado o desenvolvimento de novas formulações de produtos. Assim, nota-se que há uma tendência da união de indústrias do setor lácteo às de processamento de bebidas e beneficiamento de fruta.

Tecnologicamente, observa-se que o aproveitamento do soro de queijo para desenvolvimento de formulações alimentares 
voltadas para a alimentação humana pode ser bastante significativo, devido à variedade de nutrientes, além de possibilitar um maior controle de poluição ambiental por esse resíduo e incrementar a produtividade e lucratividade das indústrias de laticínios no Brasil.

Adicionalmente, é relevante destacar que o aproveitamento de frutas para consumo in natura e industrial pode ser bastante significativo, devido à grande variedade de nutrientes, sendo o seu processamento destinado a obtenção de produtos elaborados, já que a qualidade alimentícia e comercial do fruto in natura é influenciada pelas condições de amadurecimento e armazenamento.

\section{REFERÊNCIAS}

ARUOMA, O.I. et al. Functional benefits of ergothioneine and fruit- and vegetable-derived nutraceuticals: overview of the supplemental issue contents. Preventive Medicine, v.54, suppl.1, p.S4-S8, 2012. Disponível em: <http://www.sciencedirect.com/ science/article/pii/S0091743512001077>. Acesso em: $21 \mathrm{dez}$ 2012. doi: http://dx.doi.org/10.1016/j.ypmed.2012.04.001.

BALDISSERA, A.C. et al. Alimentos funcionais: uma nova fronteira para o desenvolvimento de bebidas protéicas a base de soro de leite. Semina: Ciências Agrárias, v.32, n.4, p.1497-1512, 2011. Disponível em: <http://www.uel.br/revistas/uel/index.php/ semagrarias/article/view/5094/9041>. Acesso em: 27 mar. 2012.

BARBOSA, A.S. et al. Utilização do soro como substrato para produção de aguardente: estudo cinético da produção de etanol. Revista Verde, v.5, n.1, p.7-25, 2010. Disponível em: $<$ http://www.gvaa.com.br/revista/index.php/RVADS/article/ download/240/240>. Acesso em: 27 mar. 2012.

BARBOSA, M.R.; ARAÚJO, E.H. Estudo da produção da enzima lactase utilizando soro de queijo e fungo filamentoso Aspergillus niger. Horizonte Científico, v.1, n.1, p.1-22, 2007. Disponível em: <http:/www.seer.ufu.br/index.php/horizontecientifico/article/ download/3786/2791>. Acesso em: 27 mar. 2012.

BASKAR, R. et al. In vitro antioxidant studies in leaves of Annona species. Indian Journal of Experimental Biology, v.45, n.5, p.480-485, 2007. Disponível em: <http://nopr.niscair.res.in/ bitstream/123456789/5257/1/IJEB\%2045\%285\%29\%20480-485. pdf $>$. Acesso em: 21 dez. 2012.

BORDIGNON JR., C.L. et al. Influência do $\mathrm{pH}$ da solução extrativa no teor de antocianinas em frutos de morango. Ciência e Tecnologia de Alimentos, v.29, n.1, p.183-188, 2009. Disponível em: $\quad<\mathrm{http}: / /$ www.scielo.br/scielo.php?script=sci arttext\&pid $=$ S0101-20612009000100028\&lng $=$ en\& $\&$ rm $=$ iso $>$. Acesso em: 21 dez. 2012. doi: http://dx.doi.org/10.1590/S010120612009000100028 .

BRANDÃO, W.A.P.L.N.T.M. et al. Bebida fermentada probiótica de soro de leite. Higiene Alimentar, v.20, n.143, p.56-59, 2006.

BRASIL. MINISTÉRIO DA AGRICULTURA, PECUÁRIA E ABASTECIMENTO. Instrução Normativa n ${ }^{\circ} 16$, de 23 de agosto de 2005. Regulamento técnico de identidade e qualidade de bebida láctea. Diário Oficial da União, Brasília, 24 de agosto de 2005.
CALDEIRA, L.A. et al. Desenvolvimento de bebida láctea sabor morango utilizando diferentes níveis de iogurte e soro lácteo obtidos com leite de búfala. Ciência Rural, v.40, n.10, p.2193-2198, 2010. Disponível em: <http://www.scielo.br/scielo. php?script=sci_arttext\&pid=S0103-84782010001000023\&lng= en\&nrm=iso>. Acesso em: 27 mar. 2012. doi: 10.1590/S010384782010005000176 .

CICHOSKI, A.J. et al. Efeito da adição de probióticos sobre as características de queijo prato com reduzido teor de gordura fabricado com fibras e lactato de potássio. Ciência e Tecnologia de Alimentos, v.28, n.1, p.214-219, 2008. Disponível em: <http:// www.scielo.br/pdf/cta/v28n1/29.pdf>. Acesso em: 14 ago. 2012. doi: http://dx.doi.org/10.1590/S0101-20612008000100030.

CRUZ, A.G. et al. Milk drink using whey butter cheese (queijo manteiga) and acerola juice as a potencial source of vitamin C. Food Bioprocess Technology, v.2, n.4, p.368-373 2009. Disponível em: $<$ http://www.springerlink.com/content/4822tp722q3j865j/fulltext. pdf $>$. Acesso em: 12 maio, 2012. doi: 10.1007/s11947-008-0059-9.

DEMBITSKY, V.M. et al. The multiple nutrition properties of some exotic fruits: Biological activity and active metabolites. Food Research International, v.44, p.1671-1701, 2011. Disponível em: <http://www.sciencedirect.com/science/article/ pii/S0963996911001608>. Acesso em: 21 dez. 2012. doi: http:// dx.doi.org/10.1016/j.foodres.2011.03.003.

DRAGONE, G. et al. Characterization of volatile compounds in an alcoholic beverage produced by whey fermentation. Food Chemistry, v.112, p.929-935, 2009. Disponível em: <http:// linkinghub.elsevier.com/retrieve/pii/S0308814608008108>. Acesso em: 20 jun. 2012. doi:10.1016/j.foodchem.2008.07.005.

ESPÍRITO SANTO, E.P. et al. Açai pulp addition improves fatty acid profile and probiotic viability in yoghurt. International Dairy Journal, v.20, n.6, p.415-422, 2010. Disponível em: <http://www. sciencedirect.com/science/article/pii/S0958694610000208>. Acesso em: 21 dez. 2012. doi: http://dx.doi.org/10.1016/j. idairyj.2010.01.002.

FACHINELLO, J.C. et al. Situação e perspectivas da fruticultura de clima temperado no Brasil. Revista Brasileira de Fruticultura, v.33, n.S1, p.109-120, 2011. Disponível em: <http://www.scielo. br/scielo.php?pid $=$ S0100-29452011000500014\&script $=$ sci arttext\&tlng=es $>$. Acesso em: 14 ago. 2012. doi: http://dx.doi. org/10.1590/S0100-29452011000500014.

$\mathrm{FAO} / \mathrm{WHO}$. Guidelines for the evaluation of probiotics in food. Food and Agricultural Organization of the United Nations and World Health Organization. Working Group Report. Geneva: WHO, 2002. Disponível em: <ftp://ftp.fao.org/docrep/fao/009/ a0512e/a0512e00.pdf>. Acesso em: 21 dez. 2012.

FARAONI, A.S. et al. Desenvolvimento de um suco misto de manga, goiaba e acerola utilizando delineamento de misturas. Ciência Rural, v.42, n.5, p.911-917, 2012. Disponível em: $<$ http://www.scielo.br/scielo.php?script=sci_arttext\&pid=S0103$84782012000500025 \& \operatorname{lng}=$ en\&nrm=iso $>$. Acesso em: $21 \mathrm{dez}$. 2012. doi: http://dx.doi.org/10.1590/S0103-84782012005000014.

FLORENTINO, E.R. et al. Caracterização do soro de queijo visando processo de aproveitamento. Higiene Alimentar, v.19, n.130, p.30-32, 2005.

GRANDI, A.Z.; ROSSI, D.A. Avaliação dos itens obrigatórios na rotulagem nutricional de produtos lácteos fermentados. Revista do 
Instituto Adolfo Lutz, v.69, n.1, p.62-68, 2010. Disponível em: $<$ http://ses.sp.homolog.bvs.br/lildbi/docsonline/get.php?id=1753>. Acesso em: 27 mar. 2012.

HARAGUCHI, F.K. et al. Proteínas do soro do leite: composição, propriedades nutricionais, aplicações no esporte e benefícios para a saúde humana. Revista de Nutrição, v.19, n.4, p.479-488, 2006. Disponível em: <http://www.scielo.br/scielo.php?pid=S1415$52732006000400007 \&$ script $=$ sci_arttext $>$. Acesso em: 14 ago. 2012. doi: http://dx.doi.org/10.1590/S1415-52732006000400007.

HOSSAIN, M.A.; RAHMAN, S.M.M. Total phenolics, flavonoids and antioxidant activity of tropical fruit pineapple. Food Research International, v.44, n.3, p.672-676, 2011. Disponível em: $<$ http:// www.sciencedirect.com/science/article/pii/S0963996910004801>. Acesso em: 21 dez. 2012. doi: http://dx.doi.org/10.1016/j. foodres.2010.11.036

JERONIMO, C.E.M. et al. Qualidade ambiental e sanitária das indústrias de laticínios do Município de Mossoró-RN. Revista Eletrônica em Gestão, Educação e Tecnologia Ambiental, v.7, n.7, p.1349-1356, 2012. Disponível em: <http://cascavel.ufsm. br/revistas/ojs-2.2.2/index.php/reget/article/view/5751/3599>. Acesso em: 14 ago. 2012.

KEMPKA, A.P. et al. Formulação de bebida láctea fermentada sabor pêssego utilizando substratos alternativos e cultura probiótica. Ciência e Tecnologia de Alimentos, Supl.28, p.170-177, 2008. Disponível em: <http://www.scielo.br/pdf/cta/ v28s0/27.pdf>. Acesso em: 20 jun. 2012. doi: 10.1590/S010120612008000500027.

KRUGER, R. et al. Desenvolvimento de uma bebida láctea probiótica utilizando como substratos soro de leite e extrato hidrossolúvel de soja. Alimentos e Nutrição, v.19, n.1, p.43-53, 2008. Disponível em: <http://serv-bib.fcfar.unesp.br/seer/index. php/alimentos/article/view/200/205>. Acesso em: 20 jun. 2012.

LEITE, M.T. et al. Canonical analysis technique as an approach to determine optimal conditions for lactic acid production by Lactobacillus helveticus ATCC 15009. International Journal of Chemical Engineering, v.2012, ID 303874, 9p, 2012. Disponível em: <http://www.hindawi.com/journals/ijce/2012/303874/>. Acesso em: 14 ago. 2012. doi:10.1155/2012/303874.

MAGALHÃES, K.T. et al. Comparative study of the biochemical changes and volatile compound formations during the production of novel whey-based kefir beverages and traditional milk kefir. Food Chemistry, v.126, p.249-253, 2011. Disponível em: <http:// linkinghub.elsevier.com/retrieve/pii/S0308814610014196>. Acesso em: 27 mar. 2012. doi: 10.1016/j.foodchem.2010.11.012.

MATOS, R.A. Desenvolvimento e mapa de preferência externo de bebida láctea à base de soro e polpa de graviola (Annona muricata). 2009. 79f. Dissertação (Mestrado em Engenharia de processos de Alimentos) - Curso de Pós-graduação em Engenharia de Alimentos, Universidade Estadual do Sudoeste da Bahia, BA.

MOREIRA, R.W.M. et al. Avaliação sensorial e reológica de uma bebida achocolatada elaborada a partir de extrato hidrossolúvel de soja e soro de queijo. Acta Scientiarum, v.32, n.4, p.435-438, 2010. Disponível em: <http://periodicos.uem.br/ojs/index.php/ ActaSciTechnol/article/viewFile/5739/5739>. Acesso em: 27 mar. 2011. doi: 10.4025/actascitechnol.v32i4.5739.
MURPHY, M.M. et al. Phytonutrient intake by adults in the united states in relation to fruit and vegetable consumption. Journal of the Academy of Nutrition and Dietetics, v.112, n.2, p.222-229, 2012. Disponível em: <http://www.ncbi.nlm.nih.gov/ pubmed/22078816>. Acesso em: 14 ago. 2012. doi: http://dx.doi. org/10.1016/j.jada.2011.08.044

OLIVEIRA, G.I.C. et al. Alimentação e suplementação de ferro em uma população de lactentes carentes. Revista de Pediatria, v.28, n.1,p.18-25, 2006. Disponível em: <http://www.pediatriasaopaulo. usp.br/upload/pdf/1153.pdf>. Acesso em: 25 jun. 2012.

OLIVEIRA, J.P.F. et al. Aspectos da comercialização de derivados lácteos em supermercados, padarias e lojas de conveniência do setor varejista de Natal/RN. Revista em Agronegócios e Meio Ambiente, v.3, n.3, p.197-212, 2010. Disponível em: <http:// www.cesumar.br/pesquisa/periodicos/index.php/rama/article/ download/1264/1130>. Acesso em: 20 mar. 2012.

PEREIRA, V.S. et al. A incorporação da variável ambiental nas agroindústrias exportadoras de derivados lácteos de Minas Gerais. Revista Contemporânea de Economia e Gestão, v.7, n.1, p.103112, 2009. Disponível em: <http://www.contextus.ufc.br/index.php/ contextus/article/download/156/60>. Acesso em: 27 jun. 2012.

PESCUMA, M. et al. Functional fermented whey-based beverage using lactic acid bacteria. International Journal of Food Microbiology, v.141, p.73-81, 2010. Disponível em: <http:// linkinghub.elsevier.com/retrieve/pii/S0168160510002217>. Acesso em: 27 mar. 2012. doi:10.1016/j.ijfoodmicro.2010.04.011.

PFLANZER, S.B. et al. Perfil sensorial e aceitação de bebida láctea achocolatada. Ciência e Tecnologia de Alimentos, v.30, n.2, p.391-398, 2010. Disponível em: < http://www.scielo.br/ pdf/cta/v30n2/16.pdf>. Acesso em: 20 mar. 2012. doi: 10.1590/ S0101-20612010000200016.

ROUTRAY, W.; MISHRA, H.N. Scientific and technical aspects of yogurt aroma and taste: a review. Comprehensive Reviews in Food Science and Food Safety, v.10, n.4, p.208-220, 2011. Disponível em: <http://onlinelibrary.wiley.com/doi/10.1111/ j.1541-4337.2011.00151.x/full>. Acesso em: 14 ago. 2012. doi: 10.1111/j.1541-4337.2011.00151.x.

SANTOS, C.T. et al. Elaboração e caracterização de uma bebida láctea fermentada com polpa de umbu (Spondias tuberosa sp.). Revista Brasileira de Produtos Agroindustriais, v.8, n.2, p.111116, 2006. Disponível em: <http://www.deag.ufcg.edu.br/rbpa// rev82/Art823.pdf>. Acesso em: 08 jun. 2010.

SANTOS, C.T. et al. Influência da concentração de soro na aceitação sensorial de bebida láctea fermentada com polpa de manga. Alimentos e Nutrição, v.19, n.1, p.55-60, 2008. Disponível em: <http://serv-bib.fcfar.unesp.br/seer/index.php/ alimentos/article/viewFile/199/204>. Acesso em: 09 jun. 2012.

SERPA, L. et al. Destino ambientalmente correto a rejeitos de queijaria e análise de viabilidade econômica. In: INTERNACIONAL WORKSHOP - Advances in Cleaner Production, 2., 2009, São Paulo, SP. Resumos... São Paulo: IWACP, 2009. p.1-10

SILVA, E.G. et al. Análise sensorial de bebida láctea fermentada sabor umbu-cajá com diferentes proporções de soro de leite. In: JORNADA DE ENSINO, PESQUISA E EXTENSÃO DA UFRPE, 10., 2010, Recife, PE. Resumos... Recife: UFRPE, 2010. p.1-3.

Ciência Rural, v.43, n.9, set, 2013. 
SILVA, F.V.G. et al. Bioactive compounds and antioxidant activity in fruits of clone and ungrafted genotypes of yellow mombin tree. Ciência e Tecnologia de Alimentos, v.32, n.4, p.685-691, 2012. Disponível em: <http://www.scielo.br/scielo.php?script=sci arttext\&pid=S0101-20612012000400008\&lng=en\&nrm=iso $>$. Acesso em: 21 dez. 2012. doi: http://dx.doi.org/10.1590/S010120612012005000101

SOARES, D.S. et al. Aproveitamento de soro de queijo para produção de iogurte probiótico. Arquivo Brasileiro de Medicina Veterinária e Zootecnia, v.63, n.4, p.996-1002, 2011. Disponível em: <http://www.scielo.br/scielo.php?script=sci pdf\&pid=S0102-09352011000400027\&lng=en\&nrm=iso\&tlng= pt>. Acesso em: 16 abr. 2012. doi: http://dx.doi.org/10.1590/S010209352011000400027.

USDA (UNITED STATES DEPARTMENT OF AGRICULTURE). Dairy: world markets and trade - July 2012. Disponível em: $<$ http://www.fas.usda.gov/psdonline/circulars/dairy.pdf $>$. Acesso em: 12 ago. 2012.

ZOELLNER, S.S. et al. Whey beverage with açai pulp as a food carrier of probiotic bacteria. Australian Journal of Dairy Technology, v.64, n.2, p.165-169, 2009. Disponível em: <http:// cat.inist.fr/?aModele $=$ afficheN\&cpsidt $=22157872>$. Acesso em: 12 ago. 2012. 